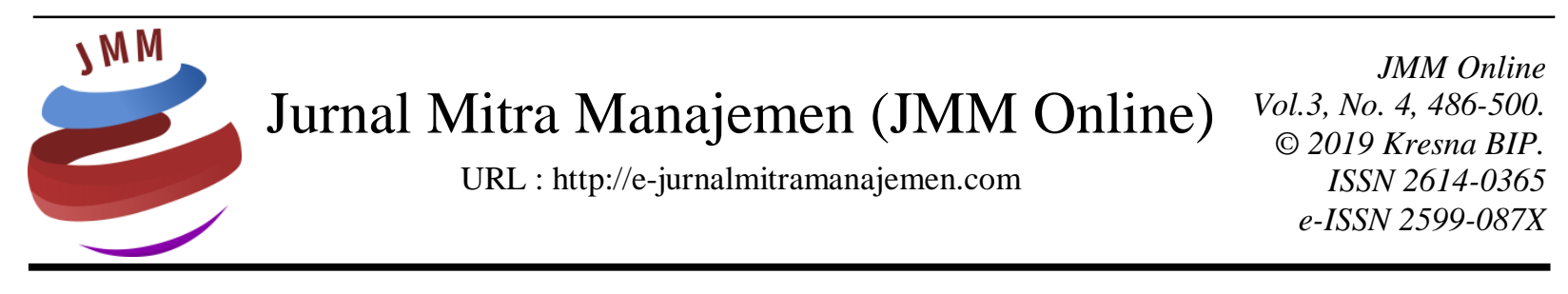

\title{
PERANCANGAN SISTEM INFORMASI PENDAFTARAN DAN PEMELIHARAAN TANAH WAKAF PEMAKAMAN UMAT ISLAM KERAMAT BEJI KOTA DEPOK
}

\author{
A.A. Gede Ajusta ${ }^{1)}$, Luthfanida ${ }^{2}$ \\ Universitas Bina Sarana Informatika
}

INFORMASI ARTIKEL

Dikirim : 18 April 2019

Revisi pertama : 23 April 2019

Diterima : 27 April 2019

Tersedia online : 04 Mei 2019

Kata Kunci : Perancangan Sistem Informasi, Pemakaman Umat Islam

Email : a.gede.age@bsi.ac.id ${ }^{1)}$, luthfani1010@bsi.ac.id ${ }^{2)}$

\section{ABSTRAK}

Pemakaman sebagai kebutuhan individu karena pada hakikatnya adalah makhluk yang bernyawa akan mati dan dikuburkan didalam tanah. Jumlah penduduk di Indonesia sangatlah banyak maka tanah yang dibutuhkan harus sesuai luasnya dengan yang akan digunakan untuk tempat pemakaman. Dengan perkembangan teknologi informasi membuat para pencari informasi dengan mudah dapat melakukan pengaksesan terhadap data atau informasi yang diinginkan. Dengan dibantu adanya dukungan teknologi komputer terbukti bahwa mekanisme kerja menjadi lebih efektif dan efisien. Komputer memang memegang peran penting dalam menunjan gkelancaran aktifitas pekerjaan, cara pengaturan data dan informasi pun dapat disampaikan kepada pihak yang membutuhkan. Penggunaan sistem basis data jugamendukung kinerja banyak instansi. SistemPembayaran Pendaftaran dan Pemeliharaan di Tanah Wakaf Pemakaman Umat Islam Keramat Beji Kota Depok masih manual. Dimana segala prosesnya mulai dari pendaftaran, pencatatan, pengolahan, penyimpanan serta laporan pembayaran masih dilakukan pengarsipan untuk data pembayaran pun menjadi mudah hilang. Sehingga dalam pembuatan laporannya membutuhkan waktu yang lama. 


\section{PENDAHULUAN \\ Latar Belakang}

Pemakaman merupakan kebutuhan setiap individu yang bernyawa karena pada hakikatnya adalah makhluk yang bernyawa akan meninggal dan dikuburkan. Jumlah penduduk Indonesia sangatlah banyak maka tanah yang dibutuhkan harus sesuai luasnya dengan yang akan digunakan untuk tempat pemakaman. Dengan perkembangan teknologi informasi membuat para pencari informasi dengan mudah dapat melakukan pengaksesan terhadap data atau informasi yang diinginkan. Informasi yang diperoleh akan lebih cepat serta akurat dan lebih menghemat waktu.

Menurut (Frieyadie \& Kristiana, 2016) Dewasa ini, lokasi pemakam di wilayah Daerah Khusus Ibukota (DKI) Jakarta, sangatlah memprihatinkan. Dengan dibantu adanya dukungan teknologi komputer terbukti bahwa mekanisme kerja menjadi lebih efektif dan efisien. Komputer memang memegang peran penting dalam menunjang kelancaran aktifitas pekerjaan, cara pengaturan data dan informasi pun dapat disampaikan kepada pihak yang membutuhkan. Penggunaan sistem basis data juga mendukung kinerja banyak instansi. Sistem Pembayaran Pendaftaran dan Pemeliharaan di Tanah Wakaf Pemakaman Umat Islam Keramat Beji Kota Depok masih manual. Dimana segala prosesnya mulai dari pendaftaran, pencatatan, pengolahan, penyimpanan serta laporan pembayaran masih dilakukan pengarsipan untuk data pembayaran pun menjadi mudah hilang. Sehingga dalam pembuatan laporannya membutuhkan waktu yang lama.

\section{Rumusan Masalah}

Berdasarkan latar belakang diatas, maka penulis merumuskan masalahnya adalah mengetahui dan menganalisa prosedur pendaftaran dan pemeliharaan di pemakaman, mengetahui kendala-kendala yang ada di dalam proses pendaftaran dan pemeliharaan pemakaman, merancang sistem informasi Pendaftaran dan Pemeliharaan Pemakaman.

\section{Tujuan Penelitian}

Berdasarkan rumusan masalah diatas, tujuan dari penulisan jurnal ini adalah untuk membuat WEB, Perancangan Sistem Informasi dan Pemeliharaan tanah wakaf pemakaman umat Islam Keramat Beji Kota Depok.

\section{KAJIAN PUSTAKA}

Menurut (Cahyaningtyas \& Iriyani, 2015) "Sistem adalah seperangkat elemen yang membentuk kumpulan atau bagan pengolahan yang mencari suatu tujuan bersama dengan mengoperasikan data dan barang pada waktu tertentu untuk menghasilkan informasi dan barang".

Menurut (Wibowo, 2015) Secara garis besar, bahasa pemrograman komputer adalah sebuah alat yang dipakai oleh para programmer komputer untuk menciptakan program aplikasi yang digunakan untuk berbagai macam keperluan. Pada tahap awal dikenal beberapa jenis bahasa pemrograman, bahasa ini berbasis teks dan berorientasi linear contohnya: Bahasa BASIC, Bahasa Clipper, Bahasa Pascal, Bahasa cobol. 
Menurut Nugroho dalam (Hendini, 2016)"Menjelaskan bahwa website atau situs dapat diartikan sebagai kumpulan halaman yang berasal dari file berisi bahasa pemograman yang saling berhubungan digunakan untuk menampilkan informasi, gambar bergerak dan tidak bergerak, suara dan atau gabugan dari semuanya itu baik yang bersifat statis maupun dinamis".

Menurut (Kurniati, 2016) "Menghubungkan antara Web Server dan Web Browser Internet dan ini merupakan gabungan dari jaringan komputer yang ada di seluruh dunia. Setelah semuanya terhubung secara fisik, Protocol TCP, IP atau networking protocol yang memungkinkan semua computer di dunia dapat berkomunikasi satu sama lainnya".

Menurut (Kurniati, 2016)"Server dalam dunia komputer adalah sebuah sistem komputer yang menyediakan jenis layanan tertentu dalam sebuah jaringan computer. Server didukung dengan prosesor yang bersifat scalable dan RAM yang besar, juga dilengkapi dengan sistem operasi khusus, yang disebut sebagai sistem operasi jaringan atau network operating system".

Menurut Muhammad Luqman dalam (Cahyaningtyas \& Iriyani, 2015) Sistem basis data adalah suatu sistem menyusun dan mengelola record menggunakan computer untuk menyimpan atau merekam serta memelihara data operasional lengkap sebuah organisasi atau perusahaan sehingga mampu menyediakan informasi yang optimal yang diperlukan pemakai untuk proses pengambilan keputusan.

Menurut (Rosa \& Shalahuddin, 2015:28) Model SDLC air terjun waterfallsering juga disebut model sekuensial linier sequential linearatau alur hidup klasik classic life cycle. Model air terjun menyediakan pendekatan alur hidup perangkat lunak secara sekuensial atau terurut dimulai dari analisi, desain, pengodean, pengujian dan tahap pendukung support.

Menurut (Rosa \& Shalahuddin, 2015:50) Entity Relationship Diagram ERD Pemodelan awal basis data yang paling banyak digunakan adalah menggunakan Entity Relationship Diagram (ERD). ERD dikembangkan berdasarkan teori himpunan dalam bidang matematika.ERD digunakan untuk pemodelan basis data relasional.

Menurut Hasugian dan Shidiq dalam (Puspitasari, 2016), sebuah model sistem yang digambarkan dengan sebuah program diagram-ER akan mengikuti pola/aturan permdelan tertentu dalam kaitannya dengan konversi ke LRS. Maka perubahan yang terjadi adalah mengikuti aturan-aturan berikut ini : setiap entitas akan diubah kebentuk kotak, sebuah atribut relasi disatukan dalam sebuah kotak bersama entitas jika hubungan yang terjadi pada diagram-ER 1:M (relasi bersatu dengan cardinality $\mathrm{M}$ ) atau tingkat hubungan 1:1 (relasi bersatu dengan cardinality yang paling membutuhkan referensi), sebuah relasi dipisah dalam sebuah kotak tersendiri (menjadi entitas baru) jika tingkat hubungannya $\mathrm{M}$ : $\mathrm{M}$ (many to many) dan memiliki foreign key sebagai primary key yang diambil dari kedua entitas yang sebelumnya saling berhubungan.

Menurut (Rosa \& Shalahuddin, 2015:161) Diagram aktvitas atau activity diagram menggambarkan workflow (aliran kerja) atau aktivitas dari sebuah sistem atau proses bisnis atau menu yang ada pada perangkat lunak. Yang perlu diperhatikan disini adalah bahwa diagram aktivitas menggambarkan aktivitas sistem bukan apa yang dilakukan aktor, jadi aktivitas yang dapat dilakukan oleh sistem. 
Menurut (Rosa \& Shalahuddin, 2015:155)Use case atau diagram use case merupakan pemodelan untuk kelakukan (behavior) sistem informasi yang akan dibuat. Use case mendeskripsikan sebuah interaksi antara satu atau lebih aktor dengan sistem informasi yang akan dibuat. Secara kasar, use case digunakan untuk mengetahui fungsi apa saja yang ada di dalam sebuah sistem informasi dan siapa saja yang berhak menggunakan fungsi-fungsi itu.

\section{METODE PENELITIAN}

\section{Waktu dan Tempat Penelitian}

Penelitian dilakukan di Pemakaman Umat Islam Keramat Beji Kota Depok Jawa Barat. Penelitian mulai dilakukan 1 Februari 2019 sampai dengan 28 Maret 2019.

Metode yang digunakan pada pengembangan perangkat lunak ini menggunakan metode waterfall (Sukamto dan Shalahuddin, 2013:28) yang terbagi menjadi lima tahapan yaitu :

1. Analisa kebutuhan Perangkat Lunak

Proses pengumpulan kebutuhan dilakukan secara intensif untuk menspesifikasi kebutuhan perangkat agar dapat dipahami perangkat lunak seperti apa yang dibutuhkan oleh user dan admin.

2. Desain

Desain perangkat lunak adalah multi langkah yang fokus pada desain pembuatan program perangkat lunak termasuk struktur data, arsitektur perangkat lunak, representasi antarmuka, dan prosedur pengkodean. Tahap ini mentranslasi kebutuhan perangkat lunak dari tahap analisis kebutuhan ke representasi desain agar dapat diimplementasikan menjadi program pada tahap selanjutnya. Sedangkan untuk mendesain penulis menggunakan Dreamweaver.

3. Pembuatan Kode Program

Pada tahap ini, desain harus di translasikan ke dalam program perangkat lunak. Hasil dari tahap ini adalah program komputer sesuai dengan desain yang telah dibuat pada tahap desain. Pada pembuatan kode program menggunakan BASIC (Beginner AllPurpose Symbolic Instruction Code).

4. Pengujian Unit

Pada tahap ini penulis melakukan pengujian unit dan sistem yang sudah dirancang menggunakan browser Mozilla firefox, pengujian dilakukan di server local (localhost) menggunakan metode blackbox.

5. Pendukung (Support) atau Pemeliharaa (Maintenance)

Tidak menutup kemungkinan sebuah perangkat lunak mengalami perubahan ketika sudah dikirimkan ke user. Perubahan bisa menjadi karena adanya kesalahan yang muncul dan tidak terdeteksi saat pengujian perangkat lunak harus beradaptasi dengan lingkungan baru. Tahap pendukung atau pemeliharaan dapat mengulangi proses pengembangan mulai dari tahap analisa spesifikasi untuk perangkat lunak baru. 


\section{Teknik Pengumpulan Data}

\section{Observasi}

Penulis melakukan penelitian dan pengamatan mengenai kegiatan Pendaftaran dan Pemeliharaan Tanah Wakaf Pemakaman yang banyak beredar di internet guna mengumpulkan data yang diperlukan untuk penulisan ini.

\section{Wawancara}

Wawancara dilakukan untuk mencari dan memeriksa kebenaran suatu informasi dan juga mendapatkan informasi secara spesifik dan jelas. Hasil dari pengamatan tersebut langsung dicatat oleh penulis dan dari kegiatan wawancara ini dapat diketahui proses dan kegiatan tersebut.

3. Studi Pustaka

Penulis melakukan tinjauan pustaka dengan mempelajari buku-buku teori, internet, jurnal sebagai bahan perbandingan atau referensi yang berhubungan dengan Perancangan Sistem Pendaftaran dan Pemeliharaan Tanah Wakaf Pemakaman.

\section{HASIL PENELITIAN DAN PEMBAHASAN}

\section{Perancangan Sistem}

1. Analisis Kebutuhan Software

Tahap analisa kebutuhan adalah tahap untuk mengidentifikasikan apa saja yang diperlukan, dibutuhkan dan dinginkan oleh para pengguna serta kebutuhan sistem itu sendiri. Dalam tahap analisis kebutuhan pngguna dapat dibedakan menjadi dua, yaitu kebutuhan pengguna atau calon pengguna dan juga kebutuhan admin atau pengurus organisasi tersebut. Kebutuhan penguuna terhadap sistem baru ini sebagai berikut :

1. Kebutuhan pengguna

Dalam web pemakaman terdapat dua pengguna yang dapat saling berinteraksi dalam lingkungan sistem, yaitu : Bagian Admin dan User. Kedua pengguna tersebut memiliki karakteristik interaksi dengan sistem yang berbedabeda dan memiliki kebutuhan informasi yang berbeda-beda sebagai berikut :

a. Skenario Kebutuhan Bagian Admin

1. Mengelola lokasi pemakaman

2. Mengelola administrasi

3. Mengelola data jenazah

4. Mengelola laporan keuangan

b. Skenario Kebutuhan User

1. Melakukan pendaftaran

2. Melakukan pembayaran

3. Melihat lokasi pemakaman

4. Melihat kriteria

5. Melihat data laporan

2. Kebutuhan Sistem

a) Admin harus login terlebih dahulu untuk dapat mengakses untuk dapat mengakses aplikasi ini dengan memasukan username dan password agar privasi tetap terjaga keamanannya.

b) Admin harus melakukan logout setelah selesai menggunakan aplikasi. 


\section{Rancangan Diagram Use Case}

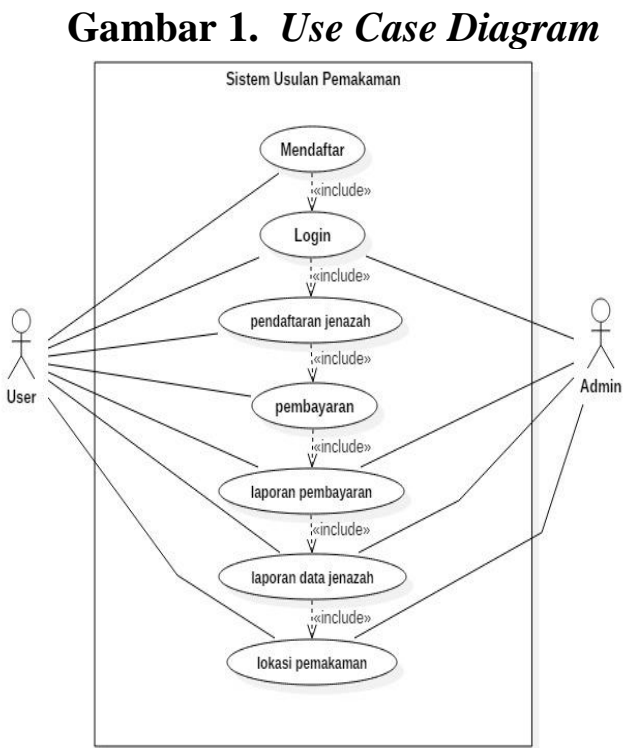

Sumber : Dokumentasi Use Case Diagram (2019)

\section{Deskripsi Use Case Pemakaman}

Tabel 1. Deskripsi Use Case Pemakaman

\begin{tabular}{|l|l|}
\hline \multicolumn{1}{|c|}{ Nama Use Case } & \multicolumn{1}{c|}{ Sistem Pendaftaran } \\
\hline Requirements & Penggunjung Melapor ketua RT \\
\hline Goal & $\begin{array}{l}\text { Bagian Pengunjung dapat langsung melakukan } \\
\text { Pendaftaran }\end{array}$ \\
\hline Pre-Conditions & Bagian Penggunjung memberikan semua berkas \\
\hline Post_conditions & Penggunjung mendapatkan perizinan \\
\hline Failed end Condition & Bagian pengunjung tidak dapat perizinan \\
\hline Actors & Penggunjung, Ketua Rt dan Pengurus Pemakaman \\
\hline Main flow/Basis path & $\begin{array}{l}\text { 1. Penggunjung melakukan pendaftaran } \\
\text { 2enggunjung memberikan semua persyaratan } \\
\text { pendaftaran. }\end{array}$ \\
& $\begin{array}{l}\text { 3. Pengunjung dapat langsung melakukan proses } \\
\text { administrasi }\end{array}$ \\
\hline Alternate flow/invariant A & $\begin{array}{l}\text { A1. Pengunjung Melakukan pendaftaran dengan } \\
\text { mengisi no pendaftaran, nama lengkap jenazah, } \\
\text { kelamin, tempat lahir, tanggal lahir, tanggal wafat, } \\
\text { agama, alamat, No hp, nama kelarga dan mengisi } \\
\text { biaya pendaftaran. }\end{array}$ \\
\hline B1. Penggunjung membatalkan pendaftaran \\
\hline Invariant B & \multicolumn{2}{|c|}{} \\
\hline
\end{tabular}




\section{Rancangan Diagram Aktivitas}

Rancangan Diagram Aktivitas Admin

Gambar 2. Rancangan Diagram Aktivitas Admin

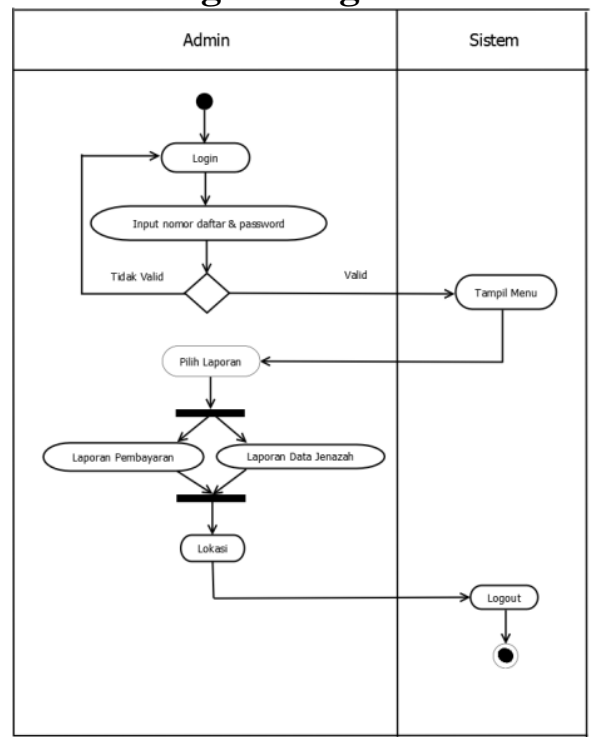

Sumber : Dokumentasi Aktivitas Admin (2019)

\section{Rancangan Diagram Aktivitas Pendaftaran}

Gambar 3. Rancangan Diagram Aktivitas Pendaftaran

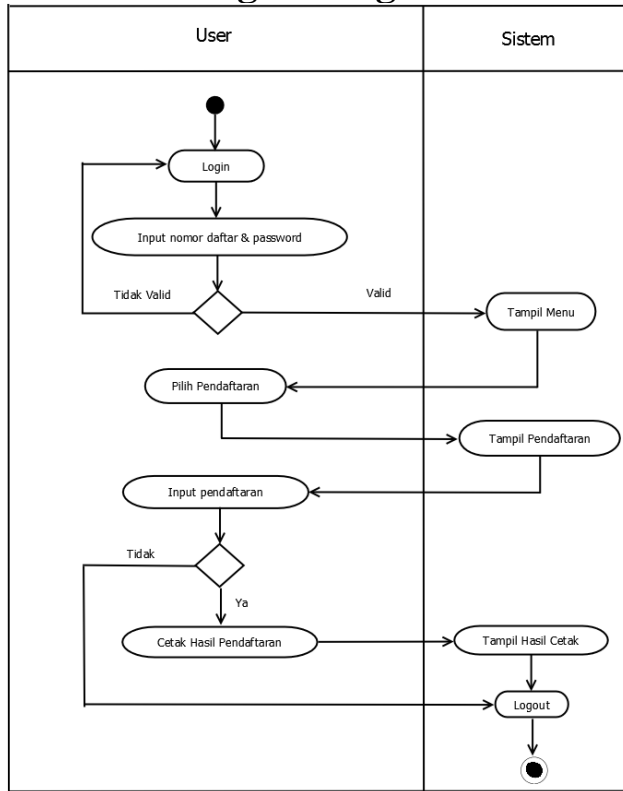

Sumber : Dokumentasi Aktivitas Pendaftaran (2019) 


\section{Rancangan Diagram Aktivitas Pembayaran}

Gambar 4. Rancangan Diagram Aktivitas Pembayaran

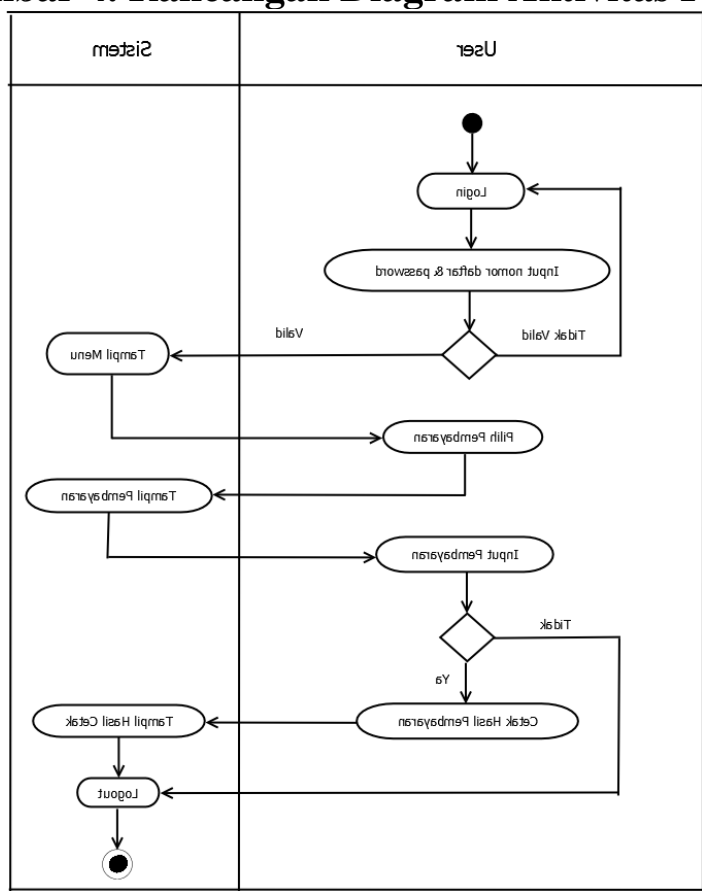

Sumber : Dokumentasi Aktivitas Pembayaran (2019)

\section{Entity Relationship Diagram (ERD)}

Gambar 5. Entity Relationship Diagram (ERD)

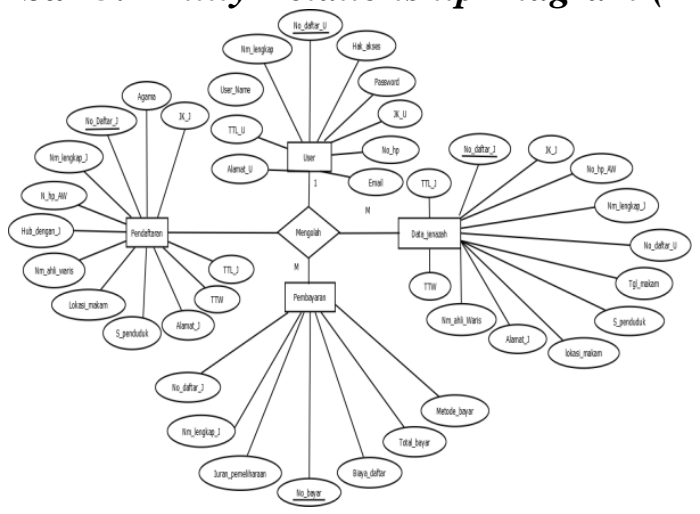

Sumber : Dokumentasi Entity Relationship Diagram (2019) 


\section{Logical Record Structure (LRS)}

Gambar 6. Logical Structure Record (LSR)

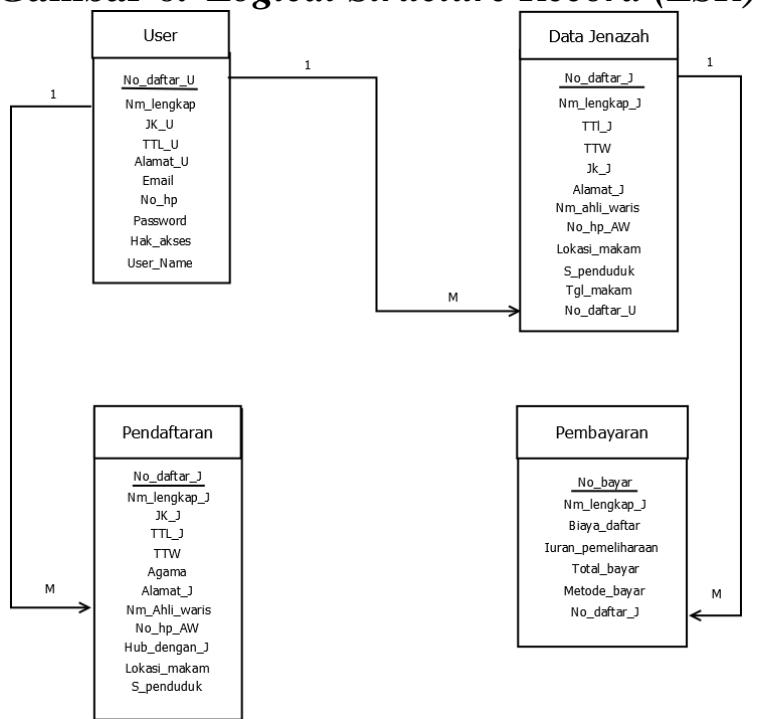

Sumber : Dokumentasi Logical Structure Record (2019)

\section{Rancangan Proto Type/Tampilan Web}

Tampilan Menu UtamaUser

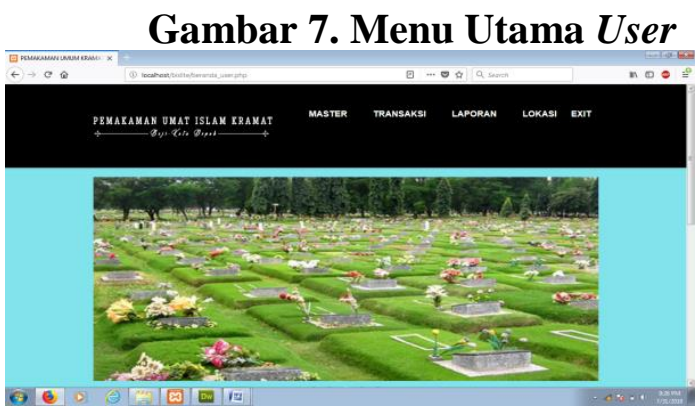

Sumber : Tampilan Web (2019)

Tampilan Menu User

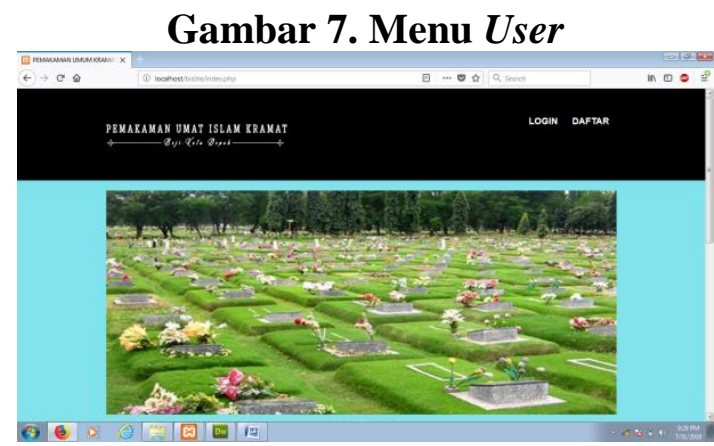

Sumber : Tampilan Web (2019) 
Tampilan Daftar User

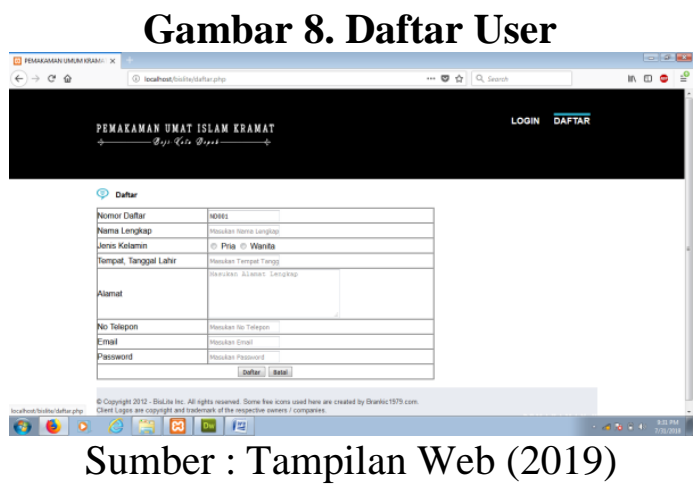

Tampilan Login

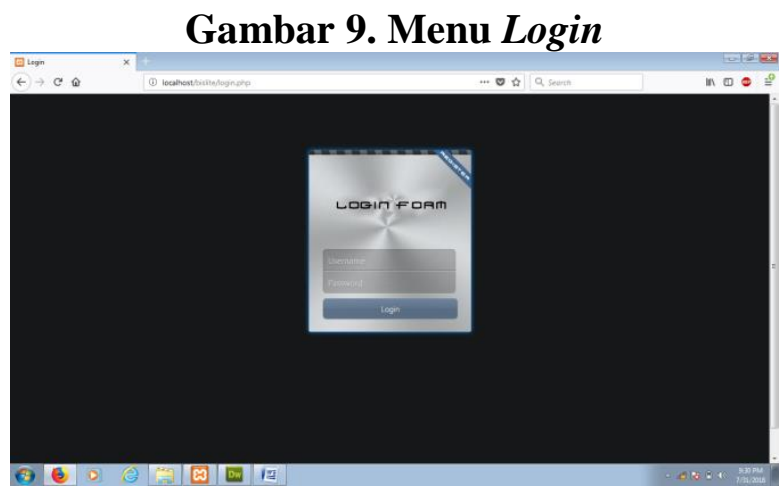

Sumber : Tampilan Web (2019)

Tampilan Menu Transaksi

\section{Gambar 10. Menu Transaksi}

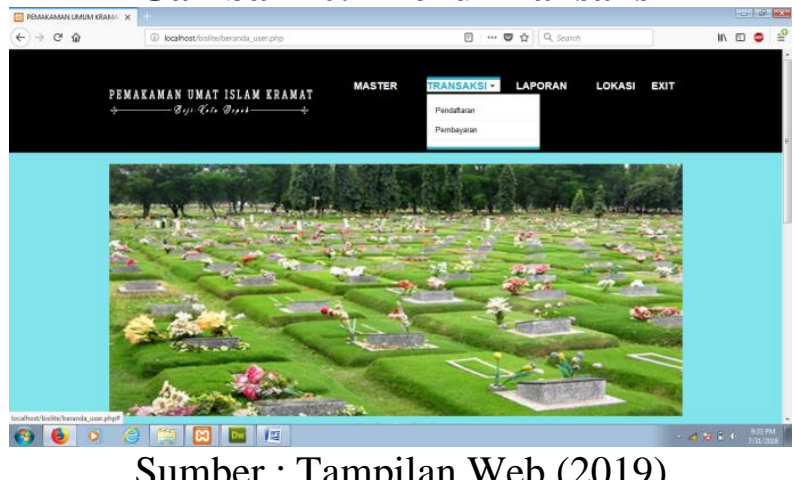

Sumber : Tampilan Web (2019) 
Tampilan Pendaftaran Jenazah

Gambar 11. Pendaftaran Jenazah

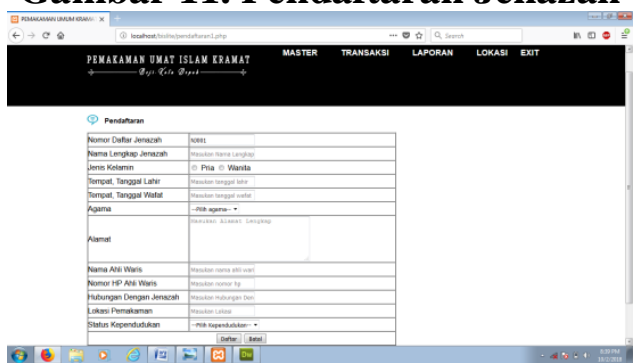

Sumber : Tampilan Web (2019)

Tampilan Pembayaran

\section{Gambar 12. Pembayaran}

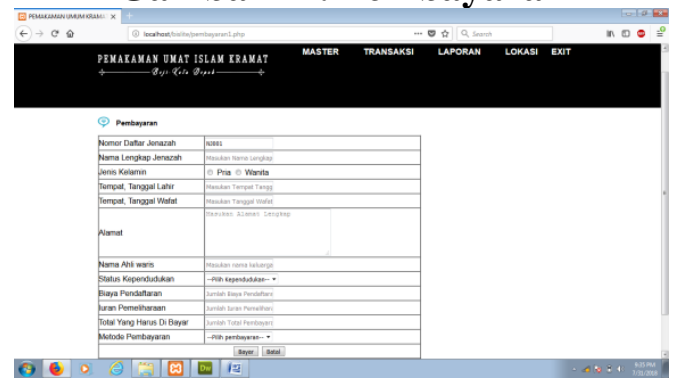

Sumber : Tampilan Web (2019)

Tampilan Menu Laporan

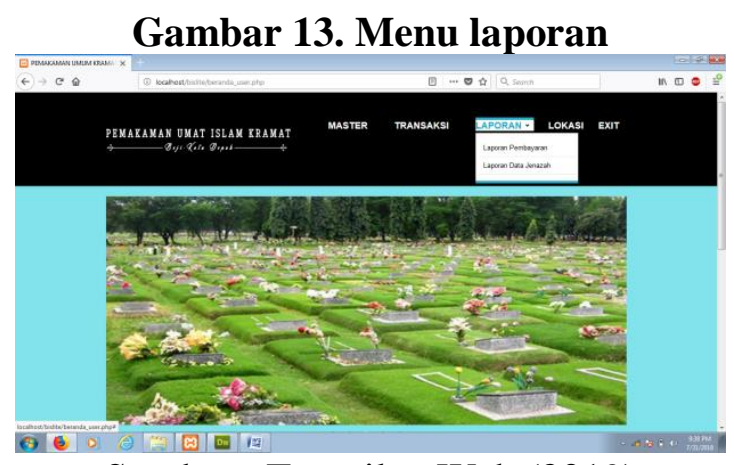

Sumber : Tampilan Web (2019)

Tampilan Laporan Pembayaran

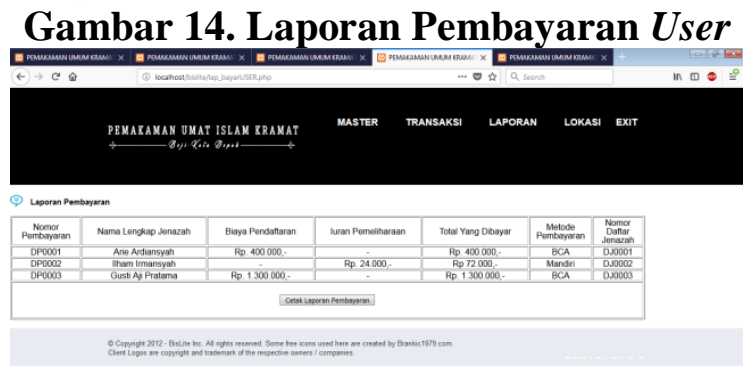

Sumber : Tampilan Web (2019) 
Tampilan Hasil Cetak Laporan Pembayaran

Gambar 15. Hasil Cetak Laporan Pembayaran User
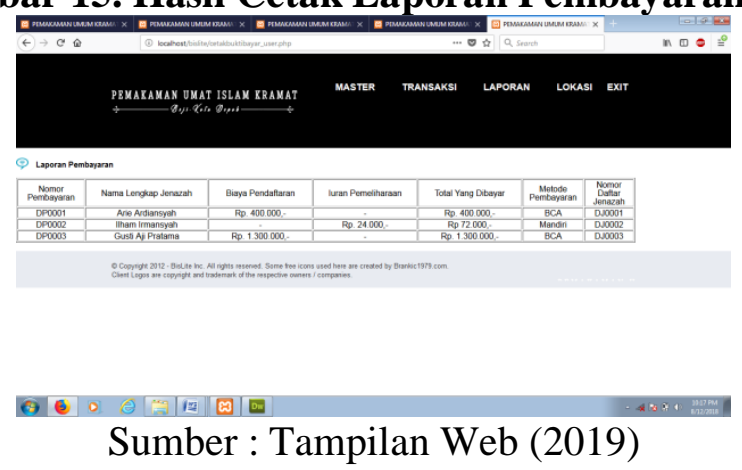

Laporan Data Jenazah

Gambar 16. Laporan Data Jenazah User

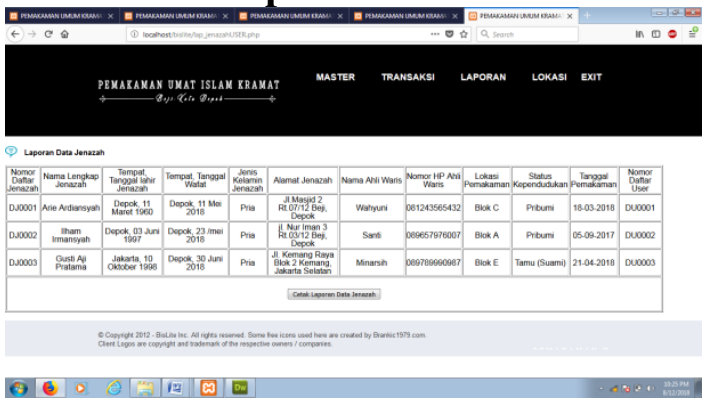

Sumber : Tampilan Web (2019)

Tampilan Hasil Cetak Laporan Data Jenazah

Gambar 17. Hasil Cetak Laporan Data Jenazah User
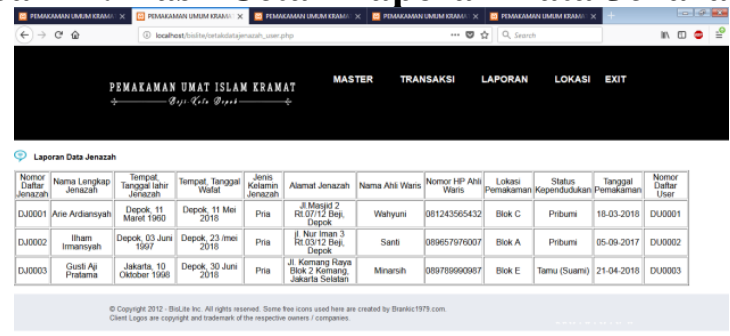

Sumber : Tampilan Web (2019)

A.A. Gede Ajusta ${ }^{1)}$, Luthfanida ${ }^{2)}$ 
Tampilan Lokasi Makam User

Gambar 18. Lokasi Makam pada User

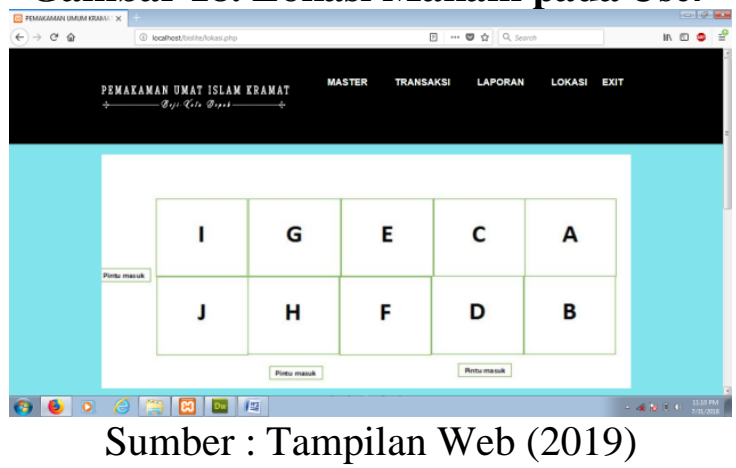

Tampilan Exit

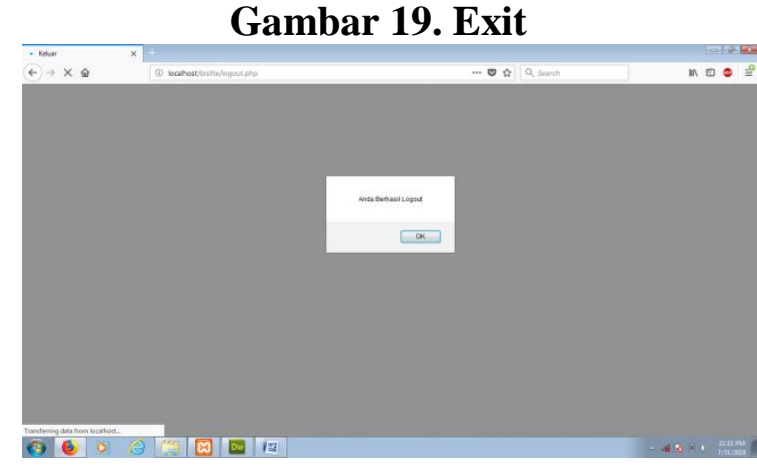

Sumber : Tampilan Web (2019)

Tampilan Beranda Admin

Gambar 20. Beranda Admin

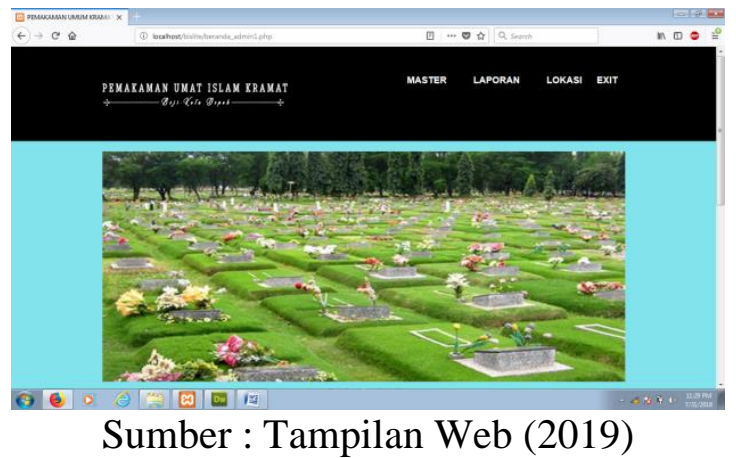

A.A. Gede Ajusta ${ }^{1)}$, Luthfanida ${ }^{2)}$ 
Tampilan laporan Pembayaran

Gambar 21. Laporan Pembayaran Admin

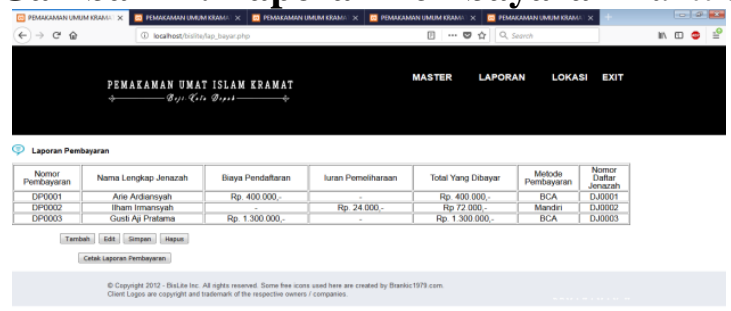

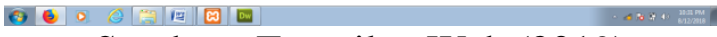

Sumber : Tampilan Web (2019)

Tampilan Laporan Data Jenazah

Gambar 22. Laporan Data Jenazah Admin

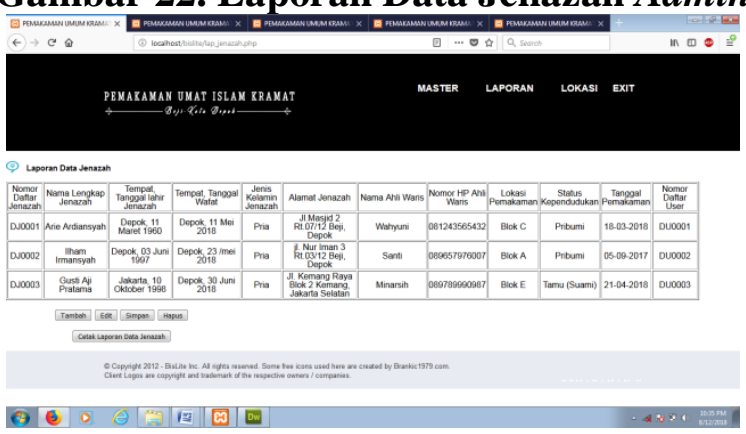

Sumber : Tampilan Web (2019)

Lokasi Makam

\section{Gambar 23. Lokasi Makam Pada Admin}

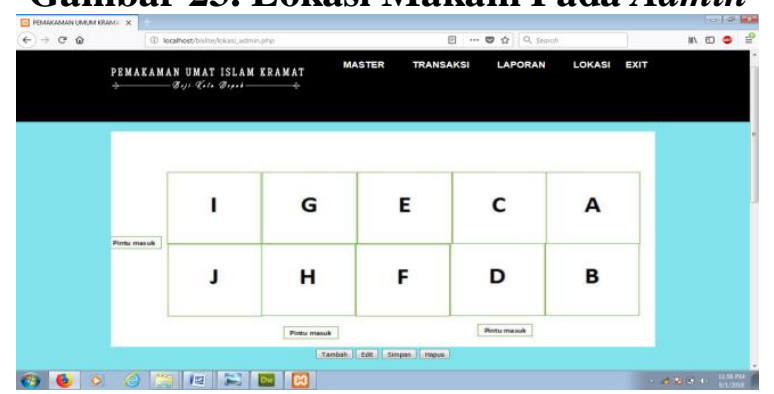

Sumber : Tampilan Web (2019)

\section{KESIMPULAN DAN SARAN}

\section{Kesimpulan}

Dalam bab ini penulis menarik kesimpulan dari seluruh pokok pembahasan pada bab-bab sebelumnya yang ada dalam tugas akhir ini.

Beberapa kesimpulan dari tugas akhir perancangan sistem pemakaman berbasis web yang penulis buat adalah :

1. Pesatnya perkembangan teknologi dan internet mempengaruhi banyak aspek dalam kehidupan sehari-hari, salah satu nya dalam bidang organisasi. 
2. Penggunaaninternet dalam organisasi kepengurusan pemakaman berfungsi sebagai alat untuk mempermudah, seperti : Pendaftaran serta pemeliharaan pemakaman.

3. Dengan adanya sistem pemakaman berbasis web ini keluarga tidak perlu repotrepot datang ke lokasi (kepengurusan) untuk mengetahui informasi mengenai pemakaman, tetapi cukup dengan mengakses situs resmi pemakaman tersebut dan mengikuti prosedur yang tercantum pada website tersebut.

\section{Saran}

Untuk menunjang keberhasilan sistem pemakaman berbasis web ini, penulis menyarankan beberapa hal yang harus dilakukan oleh para pengurus serta pengguna sistem pemakaman berbasis web. Adapun saran-saran dari penulis, antara lain :

1. Dalam pembuatan sistem pemakaman berbasis web, guna menarik minat pengguna untuk mengunjungi website tersebut serta tertarik untuk melihat informasi yang ada, hendaknya website tersebut dibuat dengan design yang menarik dan mudah untuk diopersikan (User Friendly).

2. Penulis menyarankan apabila ada pengunjung atau pengguna yang bertanya atau komplain tentang segala aktifitas yang ada pada sistem pemakaman berbasis web dapat ditanggapi dengan secepat mungkin dengan pelayanan yang maksimal agar pengunjung atau pengguna merasa nyaman.

3. Setiap sistem pemakaman berbasis web harus dikelola dengan baik agar proses administrasi berjalan dengan baik, dan diharapkan admin yang mengelola sebuah sistem pemakaman berbasis web dapat lebih aktif dalam memperbarui isi dari website tersebut. Dan dengan memiliki sistem keamanan dan backup data.

Hal-hal tersebut merupakan masukan dari penulis agar sistem pemakaman berbasis web yang diharapkan dapat memberikan hasil kerja yang berdaya guna baik sekaligus efisien dalam pemanfaatannya.

\section{DAFTAR PUSTAKA}

Ade Hendini. 2016. Pemodelan UML Sistem Informasi Monitoring Penjualan dan Stok Barang, $I V(2), 107-116$.

Agus Tedyyana Rezki Kurniati. 2016. Membuat Web Server Menggunakan Dinamic Domain. Jurnal Teknologi Informasi \& Komunikasi Digital Zone, 7, 1-10.

Cahyaningtyas, R., \& Iriyani, S. (2015). Perancangan Sistem Informasi Perpustakaan Pada Smp Negri 3 Tulakan, kecamatan Tulakan Kabupaten Pacitan. Indonesia Journal On Networking and Security, 4(2), 15-20.

Frieyadie, F., \& Kristiana, T. (2016). Rancang Bangun Sistem Informasi Administrasi Tempat Pemakaman Umum (Tpu). Konferensi Nasional Ilmu Pengetahuan Dan Teknologi, 2(1), 63-INF.68.

Kadek Wibowo. (2015). JURNAL KHATULISTIWA INFORMATIKA, 3(2), 151159.

Rosa A.S, \& Shalahuddin, M. (2014). Activity Diagram. In Rekayasa Perangkat Lunak (p. 161).

Puspitasari, D. (2016). Sistem informasi perpustakaan sekolah berbasis web, (2), 227240. 